\title{
Is there still a role for intraoperative enteroscopy in patients with obscure gastrointestinal bleeding?
}

\author{
Pedro Monsanto, Nuno Almeida, Clotilde Lérias, Pedro Figueiredo, Hermano Gouveia \\ and Carlos Sofia \\ Department of Gastroenterology. Coimbra University Hospital. Coimbra, Portugal
}

\begin{abstract}
Background: in $21^{\text {st }}$ century, endoscopic study of the small intestine has undergone a revolution with capsule endoscopy and balloon-assisted enteroscopy. The difficulties and morbidity associated with intraoperative enteroscopy, the gold-standard in the $20^{\text {th }}$ century, made this technique to be relegated to a second level.

Aims: evaluate the actual role and assess the diagnostic and therapeutic value of intraoperative enteroscopy in patients with obscure gastrointestinal bleeding.

Patients and methods: we conducted a retrospective study of 19 patients ( 11 males; mean age: $66.5 \pm 15.3$ years) submitted to $21 \mathrm{IOE}$ procedures for obscure GI bleeding. Capsule endoscopy and double balloon enteroscopy had been performed in 10 and 5 patients, respectively.

Results: with intraoperative enteroscopy a small bowel bleeding lesion was identified in 79\% of patients and a gastrointestinal bleeding lesion in 94\%. Small bowel findings included: angiodysplasia $(n=6)$, ulcers $(n=4)$, small bowel Dieulafoy's lesion $(n=2)$, bleeding from anastomotic vessels $(n=1)$, multiple cavernous hemangiomas $(n=1)$ and bleeding ectopic jejunal varices $(n=1)$. Agreement between capsule endoscopy and intraoperative enteroscopy was 70\%. Endoscopic and/or surgical treatment was used in $77.8 \%$ of the patients with a positive finding on intraoperative enteroscopy, with a rebleeding rate of $21.4 \%$ in a mean 21 -month follow-up period. Procedure-related mortality and postoperative complications have been 5 and $21 \%$, respectively.

Conclusions: intraoperative enteroscopy remains a valuable tool in selected patients with obscure GI bleeding, achieving a high diagnostic yield and allowing an endoscopic and/or surgical treatment in most of them. However, as an invasive procedure with relevant mortality and morbidity, a precise indication for its use is indispensable.
\end{abstract}

Key words: Enteroscopy. Intraoperative enteroscopy. Small bowel. Endoscopy. GI obscure bleeding.

Received: 28-10-11

Accepted: 29-11-11.

Correspondence: Pedro Monsanto. Department of Gastroenterology. Coimbra University Hospital. Praceta Mota Pinto, 3000-075. Coimbra, Portugal. e-mail: pedromonsanto@gmail.com
Monsanto P, Almeida N, Lérias C, Figueiredo P, Hermano Gouveia, Sofia $C$. Is there still a role for intraoperative enteroscopy in patients with obscure gastrointestinal bleeding? Rev Esp Enferm Dig 2012; 104: 190-196.

\section{INTRODUCTION}

Gastrointestinal (GI) bleeding is one of the most common problems seen by gastroenterologists. The source of bleeding can be identified in most cases by conventional endoscopy, but approximately $5 \%$ of all remain undiagnosed $(1,2)$. This type of bleeding is named obscure GI bleeding (OGIB) and is defined as bleeding of unknown origin that persists or recurs after a negative initial upperGI and lower-GI endoscopy. It can be classified in obscure overt and obscure occult bleeding taking into account the presence or absence of clinically evident bleeding. Because OGIB is frequently due to a lesion in the small bowel it is also known as mid-gut bleeding (3).

In the past, endoscopic conventional methods for small intestine study were sonde-type enteroscopy and push-type enteroscopy. However, if sonde-type enteroscopy has been rarely used in clinical practice $(4,5)$, push-type enteroscopy only allows the examination of the proximal small bowel with a reported diagnostic yield for OGIB between $45-78 \%$ (6-8). As a result, in $20^{\text {th }}$ century, intraoperative enteroscopy (IOE) was the gold standard for detection of lesions in the small bowel, allowing the exploration of the entire mucosa. It was in 1976 that fiber-optic endoscopes where first time used intraoperatively (9). Since then, IOE became available as a feasible alternative, with a high diagnostic yield in patients with OGIB (10). The standard procedure technique consists of a laparotomy followed by the insertion of a standard colonoscope (if possible pediatric), an enteroscope or even a standard gastroscope, through a small enterotomy. A per-orally and/or per-rectum technique can also been utilized. 
With the introduction of wireless capsule endoscopy (CE) (M2A; Given Imaging Ltd, Yoqneam, Israel) in 2000, a new era in GI imaging began $(11,12)$. Recognized its superiority over the other endoscopic methods, it became the first-line, noninvasive, diagnostic technique for the small bowel (13-18). Despite this incontestable progress, it was expected the development a new endoscopic device that would complement the inability to collect biopsies or perform therapy with CE. In 2001, Yamamoto et al. published their experience with double balloon enteroscopy (DBE) $(19,20)$. The superiority and utility of DBE for the diagnosis and therapy of small-bowel disorders has been demonstrated in several studies, with diagnostic yields varying between 25 and $92 \%$ (10). Compared to push-enteroscopy the diagnostic yield in OGIB was 73 versus $44 \%$ (21). A single balloon enteroscope and a spiral overtube enteroscope have been recently developed. Single-balloon enteroscopy performance and diagnostic yield was comparable to DBE, whereas spiral enteroscopy showed a reduction in the examination time (22-26).

Balloon-assisted enteroscopy is now considered the standard technique for endoscopic visualization of the small bowel. However, although it was judged that IOE would be excluded as a diagnostic and therapeutic procedure, there are some cases where balloon-assisted enteroscopy cannot be performed, where it investigates only partially the small bowel or where it cannot achieve endoscopic treatment. In that cases IOE is useful, providing complete endoscopic assessment of entire small intestine, exact detection and localization of extramural and/or luminal lesions with definitive surgical and/or endoscopic therapy during the same session.

The aim of our study was to evaluate the actual role of IOE and to assess its diagnostic and therapeutic value in patients with OGIB, in a third referral center.

\section{PATIENTS AND METHODS}

This is a retrospective, descriptive study, involving all patients submitted to IOE for OGIB, between 2000 and 2010. Patients were identified by use of coding software to search the medical record database. In this period, 20 consecutive patients submitted to IOE were identified: 19 for diagnosis and treatment of OGIB and 1 for planned polypectomy in Peutz-Jeghers syndrome. The 19 patients (11 males; mean age: $66.5 \pm 15.3$ years, range: $29-86$ ) submitted to $21 \mathrm{IOE}$ procedures for OGIB, comprised the final patient sample. Their charts were analyzed retrospectively regarding demographic, clinical and laboratory data. Evaluation focused on type of bleeding (overt or obscure), duration of gastrointestinal bleeding, previous investigations (endoscopic and radiological), transfusion requirements before and after the procedure, endoscopic findings and their location, agreement rate between IOE and DBE or CE, endoscopic and/or surgical therapeutic procedures, final histopathological results of surgical specimens, rebleeding rate, complications of IOE, time of follow-up and mortality. The main outcome measurements were diagnostic accuracy, therapeutic efficacy, rebleeding rate and complications. Patient follow-up was based on outpatient consultations registers and telephone interviews. All patients were submitted to extensive preoperative evaluation, and some underwent $\mathrm{CE}$ and/or DBE that were introduced in our hospital in 2001 and 2005, respectively.

Intraoperative enteroscopy was performed by a team of surgeons and gastroenterologists. After a median laparotomy, adhesiolysis was performed and the small intestine was explored. If no source of OGIB was identified the endoscope was introduced via a transoral and/or transanal route or by a mid-small bowel enterotomy. Each approach took into consideration the findings of VCE, when it was performed prior to IOE. The first enteroscopies were done using conventional colonoscope or gastroscope. The latter enteroscopies were performed using a Fujinon FN450-P5/20 enteroscope (Fujinon Inc, Japan), 200-cm working length, without overtubeballoon equipment. If the transoral route was adopted, after a new investigation of upper digestive tract the endoscope was pushed forward into the jejunum, facilitated with duodenum mobilization by the surgeon, and continued through the small intestine, as far as possible, helped by the surgeon that pleated the small intestine over endoscope. If an enterotomy was necessary, the surgeon prepared the small bowel enterotomy and then placed the endoscope through a sterile sleeve in the intestinal lumen. The endoscope was then pushed up to the duodenum and next down to the cecum. Room air as insufflation agent was used. In IOE, although the gastroenterologist operates the endoscope, the insertion and withdraw of the endoscope is performed by the surgeon, therefore it is necessary a perfect collaboration of both. The mucosa was cautiously observed during insertion of endoscope, because of trauma induced by intubation and bowel manipulation could be wrongly confounded with angiectasias upon withdrawal of the endoscope. If a lesion or bleeding source was detected, endoscopic (argon plasma coagulation) or surgical treatment was performed in the same surgical session if necessary. Informed consent was obtained from all patients and/or their parents for all procedures.

Continuous variables were expressed as mean with standard deviation and range. Categorical variables were expressed with percentage. Statistical analysis of data was performed using Statistical Package for Social Sciences (SPSS) version 16.0 for Windows (SPSS, Inc., Chicago, USA).

\section{RESULTS}

Of the 19 patients submitted to IOE for evaluation of OGIB, 17 (89\%) presented with obscure overt bleeding (i.e, melena or hematoquezia) and $2(11 \%)$ with obscure occult bleeding. On average, the mean duration of OGIB history was $3.3 \pm 6.4$ months (range: $0-24$ ) and a mean of $17.5 \pm 18.9$ (range: $2-50$ ) blood units were transfused preoperatively (Table I). All patients underwent at least one upper and lower endoscopy, previous to IOE. Capsule endoscopy and DBE had been performed in $10(53 \%)$ and 
Table I. Demographic and clinical history

\begin{tabular}{lll}
\hline & $n /$ Mean $\pm S D$ & Range \\
\hline Patients & 19 & - \\
Male/Female & $11 / 8$ & - \\
Age (years) & $66.5 \pm 15.3$ & $29-86$ \\
Mean blood transfusions (units) & $17.5 \pm 18.9$ & $2-50$ \\
\hline
\end{tabular}

$5(26 \%)$ patients, respectively. When performed, DBE was preceded by VCE in all cases. Nine patients were referred directly to IOE without previous DBE or VCE: in 3 because these exams had not been introduced yet in our Digestive Endoscopy Unit and in 6 because it was not possible to perform emergent VCE or DBE and the clinical situation needed urgent resolution. The modalities of preoperative diagnostic evaluation of OGIB are listed in table II.

In total, 21 IOE were performed (one patient required 3 IOE). They were done by transoral approach exclusively $(n=6)$, by combined transoral and transanal approaches $(n=2)$ or transparietal with enterotomy $(n=13)$, however, in two of these cases an additional enterotomy was required to avoid overdistension of the mesentery.

A gastroscope or colonoscope was used in 11 procedures and a $200 \mathrm{~cm}$ working length enteroscope in 10 . The entire exploration of small intestine was possible in $63 \%$ of patients. In fact, in the 6 patients where was used exclusively the transoral approach, only in $3(50 \%)$ the total length of the intestine was explored. This was due to the fact that a lesion or bleeding source has already been detected in the explored segment, making unnecessary extending the procedure. In the same way, of the 11 patients where was used an enterotomy approach, only in $2(18 \%)$ the ileum was explored: in one case to evaluate the terminal ileum and an enterocolic anastomosis and in other case to assess a bleeding subepithelial lesion previously identified in CE.

\section{Endoscopic findings}

A small bowel bleeding lesion was identified in 15 (79\%) patients. However, despite no small intestine lesion was

\section{Table II. Preoperative diagnostic evaluation of OGIB}

\begin{tabular}{|c|c|}
\hline Procedure & $(\%) n$ \\
\hline Esophagogastroduodenoscopy & $19(100 \%)$ \\
\hline Colonoscopy & $19(100 \%)$ \\
\hline $\mathrm{CE}$ & $10(53 \%)$ \\
\hline DBE & $5(26 \%)$ \\
\hline Mesenteric arteriography & $11(58 \%)$ \\
\hline 99mTc-labeled RBC radionuclide study & $6(32 \%)$ \\
\hline Entero CT scan & $2(11 \%)$ \\
\hline Small bowel contrast study & $1(5 \%)$ \\
\hline
\end{tabular}

found in $4(21 \%)$ patients, in 3 of them the IOE identified an outside small intestine source of bleeding. So, the diagnostic yield of IOE, for OGIB lesions, was 94\% (18/19 patients).

The leading intra-operative endoscopic findings included angiodysplasia in $6(32 \%)$ and ulcers in $4(21 \%)$ patients. The etiology of ulcerative lesions was attributed to non-steroidal anti-inflammatory drugs $(\mathrm{n}=2)$, cytomegalovirus enteritis $(\mathrm{n}=1)$ and chronic small bowel ischemia $(n=1)$. The other findings were small bowel Dieulafoy's lesion $(n=2)$, bleeding from anastomotic vessels after ileocolic resection $(n=1)$, multiple cavernous hemangiomas $(\mathrm{n}=1)$ (Figs. 1-5) and bleeding ectopic

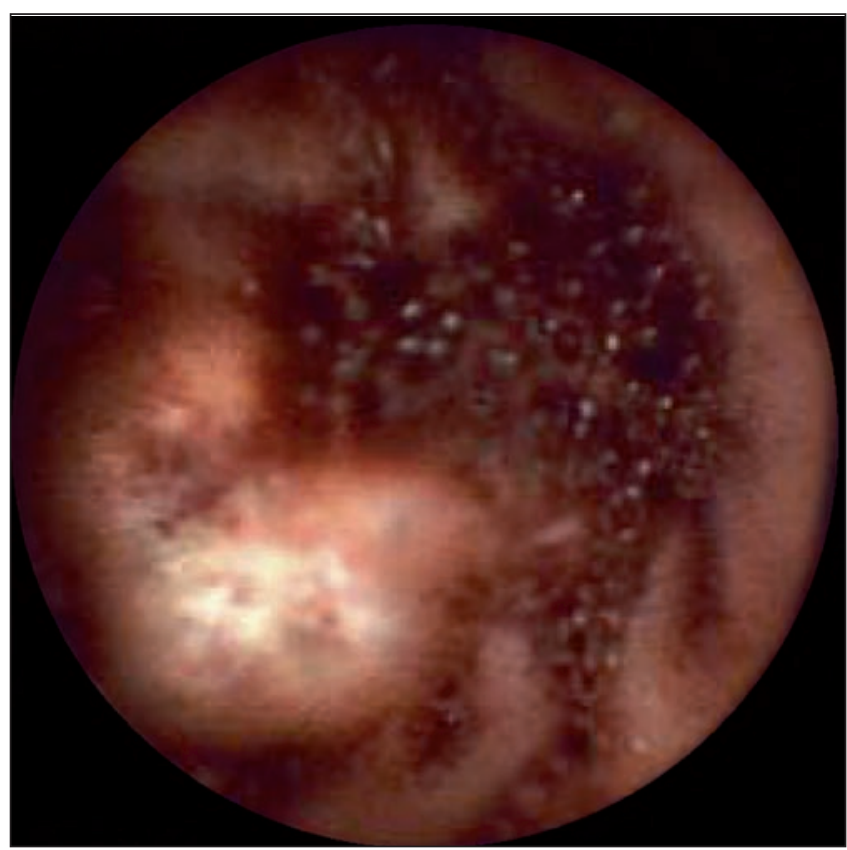

Fig. 1. Video capsule endoscopy: active bleeding cavernous hemangioma in the jejunum.

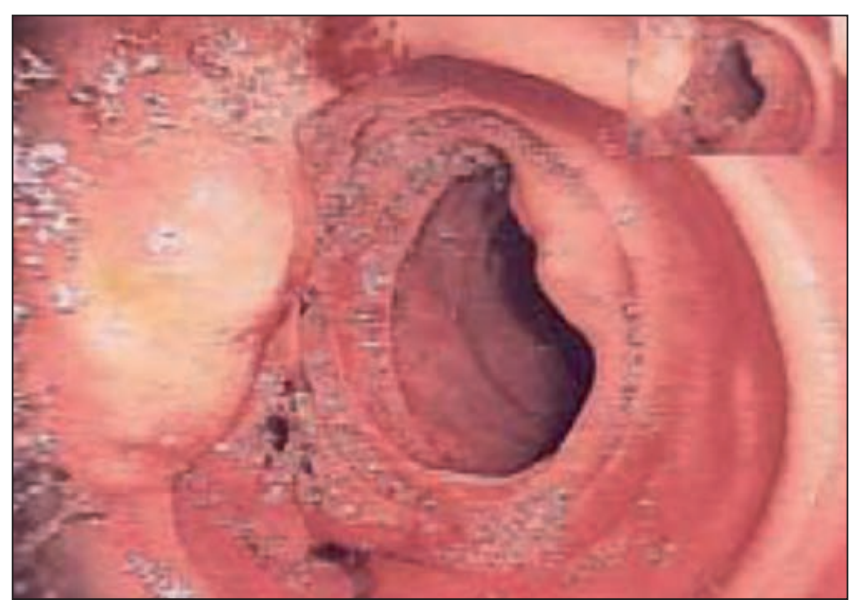

Fig. 2. Intraoperative enteroscopy: two cavernous hemangiomas at the jejunum. 


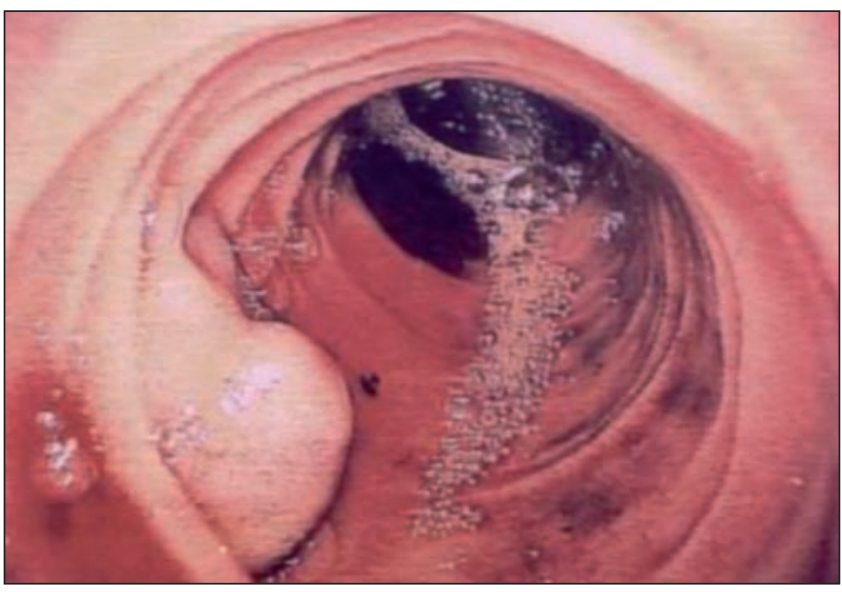

Fig. 3. Intraoperative enteroscopy: one cavernous hemangioma at the ileon.

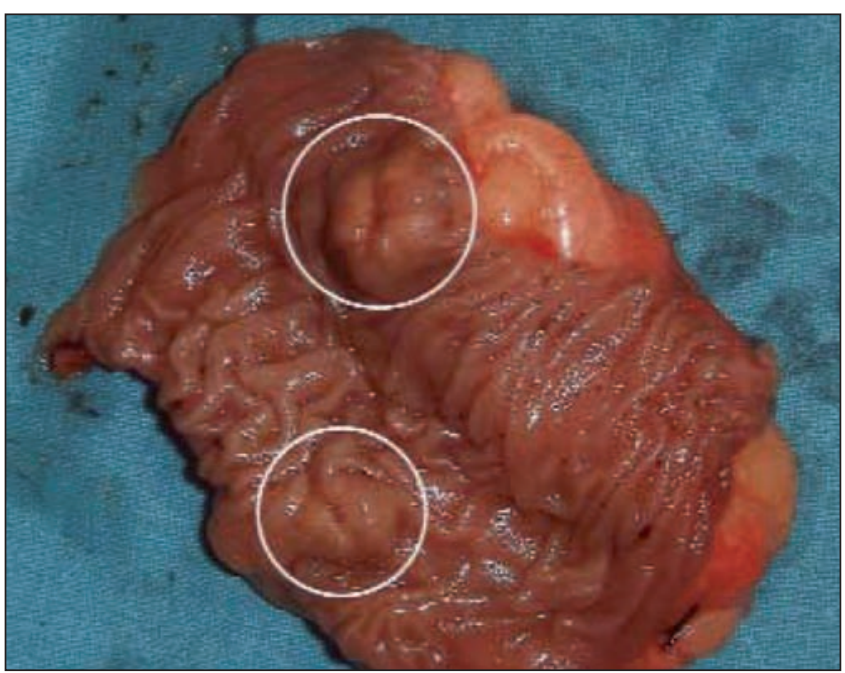

Fig. 4. Surgical specimen: two cavernous hemangiomas at the jejunum.

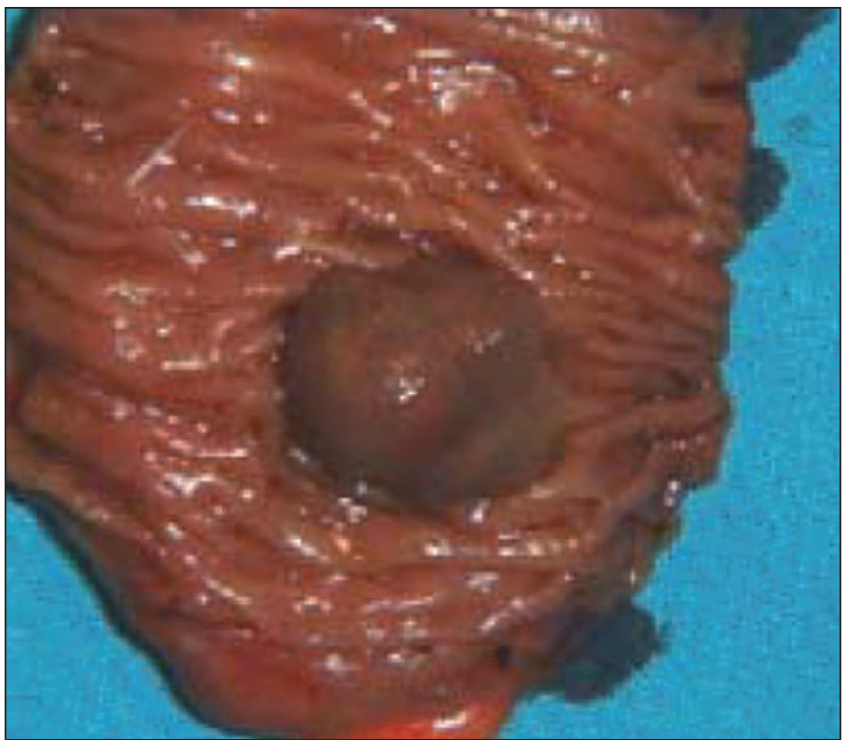

Fig. 5. Surgical specimen: one cavernous hemangioma at the ileon. jejunal varices $(n=1)$. In $4(21 \%)$ patients no small bowel lesion was identified, however a colonic diverticular bleeding, a duodenal angiodysplasia and a duodenal ulcer were detected under IOE and assumed as the source of the bleeding (Table III).

\section{Comparison with CE and DBE}

Ten patients were submitted to $\mathrm{CE}$. The capsule reached the cecum at the end of the procedure in all procedures and allowed the entire visualization of the small bowel. Agreement with IOE was $70 \%$, with discordant findings in 3 cases: in case no. $1 \mathrm{CE}$ visualized one subepithelial small bowel lesion that was not recognized in $\mathrm{IOE}$; in case no. $2 \mathrm{CE}$ visualized one jejunal angiodysplasia but IOE only identified a duodenal angiodysplasia; in case no. $3 \mathrm{CE}$ visualized a subepithelial bleeding lesion that IOE confirmed to be a bleeding angiodysplasia.

Five patients underwent DBE. The reasons to perform IOE in these patients were: incomplete investigation of the small bowel (3), unsuccessful endoscopic treatment with major bleeding (1), and precise localization and definitive surgical treatment of a small bowel lesion (1). In patients in whom IOE and DBE explored the same intestinal seg-

Table III. Diagnostic and procedures of IOE

\begin{tabular}{|c|c|c|c|}
\hline Lesions & $\begin{array}{l}n \\
(19)\end{array}$ & $\begin{array}{l}\text { Endoscopic } \\
\text { procedure }\end{array}$ & $\begin{array}{l}\text { Surgical } \\
\text { procedure }\end{array}$ \\
\hline $\begin{array}{l}\text { Small bowel } \\
\text { angiodysplasia }\end{array}$ & 6 & APC (2) & Segmental resection (5) \\
\hline Ulcers & 4 & & \\
\hline $\begin{array}{l}\text { NSAIDs } \\
\text { Cytomegalovirus }\end{array}$ & 2 & - & Segmental resection (2) \\
\hline enteritis & 1 & - & - \\
\hline $\begin{array}{l}\text { Chronic small bowel } \\
\text { ischemia }\end{array}$ & 1 & - & - \\
\hline Dieulafoy's lesion & 2 & - & Segmental resection (2) \\
\hline $\begin{array}{l}\text { Bleeding from anastomotic } \\
\text { vessels }\end{array}$ & 1 & - & Reanastomosis (1) \\
\hline Cavernous hemangiomas & 1 & - & Segmental resection (1) \\
\hline $\begin{array}{l}\text { Bleeding ectopic jejunal } \\
\text { varices }\end{array}$ & 1 & - & Segmental resection (1) \\
\hline Normal small bowel finding & 4 & - & \\
\hline $\begin{array}{l}\text { Colonic diverticular } \\
\text { bleeding }\end{array}$ & 1 & - & Colonic resection (1) \\
\hline Duodenal angiodysplasia & 1 & - & - \\
\hline Duodenal ulcer & 1 & - & - \\
\hline
\end{tabular}


ments there were no discordant findings. Also of note, after the introduction of DBE, the number of patients submitted to IOE increased from 1.3 to 2.2/year.

\section{Therapy performed}

Of the 18 patients with a positive finding on IOE, 14 $(77.8 \%)$ were submitted to endoscopic $(1 / 14,7.1 \%)$, surgical treatment $(12 / 14,85.8 \%)$ or a combined approach $(1 / 14,7.1 \%)$. Argon-plasma coagulation was used in 2 patients. Segmental resection was performed in 11 patients, a reanastomosis in one and a colonic resection in another (Table III).

\section{Morbidity, mortality and long-term results}

Six patients (31.6\%) died after a mean follow-up period of $21 \pm 24$ months (1-72). Mortality associated to IOE was $5 \%$ : one patient developed postoperative cardiovascular complications and died after cardiac arrest within 24 hours after IOE. Of the remaining 5 patients, 3 died in relation with small bowel disease (cytomegalovirus enteritis, chronic small bowel ischemia and rebleeding from small bowel angiodysplasia).

Of the patients submitted to endoscopic and/or surgical treatment, rebleeding occurred in $21.4 \%$ (3/14): small bowel angiodysplasia treated endoscopically (1), development of new ectopic jejunal varices (1) and rebleeding from anastomotic vessels (1). Overall rebleeding rate was $26.3 \%$. Postoperative complications included prolonged ileus (2 patients) and adverse cardiovascular events (2 patients).

\section{DISCUSSION}

In the beginning of $21^{\text {st }}$ century, $\mathrm{CE}$ and balloon-assisted enteroscopy revolutionized the endoscopic exploration of the small intestine, particularly in the management of OGIB. Capsule endoscopy is now the preferred method of evaluation because it is noninvasive, well-tolerated, allows the entire examination of small bowel and provides an approximate localization of the site of the bleeding, guiding further investigations and treatments. Balloon-assisted enteroscopy is considered the second-line examination for patients with OGIB and positive findings in CE requiring further exploration or therapeutic intervention $(10,27)$. However, the reported rates of total small bowel intubation vary widely (ranging from 0 to $86 \%$ ), hampered by the presence of intestinal adhesions of previous surgery, obesity or with operators with less experience $(19,20,23,25,28-30)$. Nevertheless, when balloon enteroscopy approach is directed by $\mathrm{CE}$ findings, one-side procedure was sufficient to achieve the lesion in almost $90 \%$ of examinations (31).

Due to these new developments, indications of IOE have decreased during last years. It is now used as the ultimate procedure in patients where balloon-assisted enteroscopy cannot be performed or fails to investigate the entire small bowel and to achieve a definitive treatment. Curiously, in our center, the number of IOE procedures has increased after the implementation of DBE. This perhaps may be explained by a better accuracy in the diagnosis of mid-gut bleeding with the new endoscopic (CE and DBE) and imaging (CT, angiography) techniques, remaining the IOE as a last choice, namely during emergent situations when DBE was unavailable.

The main drawback of IOE is the need of laparotomy or laparoscopy, with inherent risk of adhesions formation, perforation, abdominal and wound infections and ventral hernias. Besides surgical morbidity, other complications include serosal tears, avulsion of mesenteric veins, prolonged ileus and cardiovascular events during convalescence period. It has the advantage of making possible the evaluation of all small intestine, providing a immediate surgical resolution of pathological findings. In fact, the rate of complete enteroscopy with IOE is superior to balloonassisted enteroscopy, ranging between 57 and $100 \%$ in most series (32-41). In our series IOE was able to explore the complete small intestine in $63 \%$ of patients: $50 \%$ in peroral approach versus $82 \%$ in enterotomy approach. Many reports attest the failure to reach the terminal ileum in a considerable number of patients in the per-oral approach, as the limited work length of the endoscopes doesn't permit a complete inspection of small bowel $(34,36,37)$.

The ability of IOE to identify small bowel lesions has been remarkable, ranging between 70 to $100 \%$, allowing a therapeutic procedure in 40 to $100 \%$ of these cases, with a recurrent bleeding rate between 6 to $52 \%$ (32-41). This is also reflected in our results where IOE was diagnostic in $94 \%$ of the cases (18/19), allowing a endoscopic and/or surgical therapeutic procedure in $77.8 \%$ (14/18), with a rebleeding rate of $21.4 \%$ (3/14). In 3 patients a duodenal or colonic source of bleeding was identified during IOE. The reasons why these lesions have been missed by upperGI or lower-GI endoscopy are unclear. Nevertheless, in 7 to $24 \%$ of patients with OGIB that perform an small intestine study with CE or DBE, the source of blood loss is found in the stomach or the colon, within reach of conventional endoscopy (42-44). The most common findings by IOE were vascular lesions (angiodysplasia and Dieulafoy's lesion) and ulcers. These are typical potential causes of OGIB in older patients, in accordance to the age sample of our series. The ability of IOE to identify a lesion and allow a definitive treatment was $77.8 \%$ (14/18): 1 was treated endoscopically with argon plasma coagulation, 12 were submitted to surgical treatment and 1 by a combined surgical and endoscopic approach. The other 4 patients did not require or was not indicated any intraoperative treatment. As in other series, surgery was the most frequently employed modality, taking advantage of the fact that on the other side of the small bowel worked a surgeon. Surgical treatment can grant definitive resolution and lower rates of rebleeding. Although the time of follow-up has not been 
extensive, taking into account just the patients submitted endoscopic and/or surgical treatment, the rebleeding rate was $21.4 \%$, similar to other series values (32-41). In fact, rebleeding is the main problem arising from the management of OGIB. Vascular diseases such as angiodysplasia are more likely to rebleed than nonvascular diseases, but surgically treated patients had lower frequency of rebleeding rate than patients submitted to medical or endoscopic treatment $(28,45)$. Other potentially causes of rebleeding are incomplete surgical resection in a multifocal intestine involvement or postoperative development of new lesions in other spared segments (32).

Ten patients underwent CE previously to IOE. In patients in whom IOE and DBE explored the same intestinal segments there were discordant findings in 3 cases, as described above. CE has been previously compared with IOE in patients with OGIB. CE had sensitivity, specificity and positive and negative predictive values of 95, 75, 95 and $86 \%$, respectively with an agreement rate with IOE in $93 \%$ of the cases (41). In our series, agreement between CE with IOE was good, achieving a value of $70 \%$.

The main disadvantage of IOE over other techniques is his surgical morbidity and non-negligible associated mortality rate. Procedure-related mortality and postoperative complications have been 5 and $21 \%$, respectively, and although most studies report a low procedure-related mortality, it has been up 17\% in some series (32-41). This main disadvantage, associated to the development of new deep enteroscopy modalities, had relegated this technique as a last option in the management of OGIB. In fact, after the introduction of assisted-balloon enteroscopy in our center, 90 patients with OGIB were managed with DBE and only 11 with IOE. However, in our series, five patients underwent IOE after an initial DBE, pointing out that IOE can complement balloon-assisted enteroscopy in some precise indications.

In conclusion, although IOE remains useful in the management of OGIB, achieving a diagnostic yield of $94 \%$ and allowing a definitive treatment in $77.8 \%$, it should be reserved for patients with massive, continuous or recurrent gastrointestinal bleeding when other less invasive methods have failed to treat the source of hemorrhage or were unable to complete the investigation of the small bowel.

\section{ACKNOWLEDGEMENTS}

We thank Dr. Miguel Areia for providing the photographs.

\section{REFERENCES}

1. Zuckerman GR, Prakash C, Askin MP, Lewis BS. AGA technical review on the evaluation and management of occult and obscure gastrointestinal bleeding. Gastroenterology 2000;118:201-21.

2. Lewis BS. Small intestinal bleeding. Gastroenterol Clin North Am 1994;23:67-91.
3. Ell C, May A. Mid-gastrointestinal bleeding: capsule endoscopy and push-and-pull enteroscopy give rise to a new medical term. Endoscopy 2006;38:73-5.

4 López MJ, Cooley JS, Petros JG, Sullivan JG, Cave DR. Complete intraoperative small-bowel endoscopy in the evaluation of occult gastrointestinal bleeding using the sonde enteroscope. Arch Surg 1996;131:272-7.

5. Gostout CJ. Sonde enteroscopy: technique, depth of insertion, and yield of lesions. Gastrointest Endosc Clin North Am 1996;6:777-92.

6. Chong J, Tagle M, Barkin JS, Reiner DK. Small bowel push-type fiberoptic enteroscopy for patients with occult gastrointestinal bleeding or suspected small bowel pathology. Am J Gastroenterol 1994;89: 2143-6.

7. Davies GR, Benson MJ, Gertner DJ, Van Someren RM, Rampton DS, Swain CP. Diagnostic and therapeutic push type enteroscopy in clinical use. Gut 1995;37:346-52.

8. Landi B, Tkoub M, Gaudric M, Guimbaud R, Cervoni JP, Chaussade S, et al. Diagnostic yield of push-type enteroscopy in relation to indication. Gut 1998;42:421-5.

9. Greenberg GR, Phillips MJ, Tovee EB, Jeejeebhoy KN. Fiberoptic endoscopy during laparotomy in the diagnosis of small intestinal bleeding. Gastroenterology 1976;71:133-5.

10. Raju GS, Gerson L, Das A, Lewis B. American Gastroenterological Association. American Gastroenterological Association (AGA) Institute technical review on obscure gastrointestinal bleeding. Gastroenterology 2007; 133:1697-717.

11. Appleyard M, Fireman Z, Glukhovsky A, Jacob H, Shreiver R, Kadirkamanathan $\mathrm{S}$, et al. A randomized trial comparing wireless capsule endoscopy with push enteroscopy for the detection of small-bowel lesions. Gastroenterology 2000;119:1431-8.

12. Iddan G, Meron G, Glukhovsky A, Swain P. Wireless capsule endoscopy. Nature 2000;405:17.

13. Lewis BS, Swain P. Capsule endoscopy in the evaluation of patients with suspected small intestinal bleeding: results of a pilot study comment. Gastrointest Endosc 2002;56:349-53.

14. Ell C, Remke S, May A, Helou L, Henrich R, Mayer G. The first prospective controlled trial comparing wireless capsule endoscopy with push enteroscopy in chronic gastrointestinal bleeding. Endoscopy 2002; 34:685-9.

15. Adler DG, Knipschield BA, Gostout C. A prospective comparison of capsule endoscopy and push enteroscopy in patients with GI bleeding of obscure origin. Gastrointest Endosc 2004:59:492-8.

16. Pennazio M, Santucci R, Rondonotti E, Abbiati C, Beccari G, Rossini $\mathrm{FP}$, et al. Outcome of patients with obscure gastrointestinal bleeding after capsule endoscopy: report of 100 consecutive patients. Gastroenterology 2004;126:643-53.

17. Saurin JC, Delvaux M, Gaudin JL, et al. Diagnostic value of endoscopic capsule in patients with obscure digestive bleeding: blinded comparison with video push-enteroscopy. Endoscopy 2003;35:576-84.

18. Caunedo A, Rodríguez-Téllez M, García-Montes JM, Gómez-Rodríguez BJ, Guerrero J, Herrerías JM Jr, Pellicer F, Herrerías JM. Usefulness of capsule endoscopy in patients with suspected small bowel disease. Rev Esp Enferm Dig 2004;96:10-21.

19. Yamamoto H, Sekine Y, Sato Y, Higashizawa T, Miyata T, Iino S, et al. Total enteroscopy with a nonsurgical steerable double-balloon method. Gastrointest Endosc 2001;53:216-20.

20. Yamamoto H, Kita H, Sunada K, Hayashi Y, Sato H, Yano T, et al. Clinical outcomes of double-balloon endoscopy for the diagnosis and treatment of small-intestinal diseases. Clin Gastroenterol Hepatol 2004;2:1010-6.

21. May A, Nachbar L, Schneider M, Ell C. Prospective comparison of push enteroscopy and push-and pull enteroscopy in patients with suspected small-bowel bleeding. Am J Gastroenterol 2006;101:2016-24.

22. Hartmann D, Eickhoff A, Tamm R. Balloon-assisted enteroscopy using a single-balloon technique. Endoscopy 2007;39(Supl. 1):E276.

23. Tsujikawa T, Saitoh Y, Andoh A, Imaeda H, Hata K, Minematsu H, et al. Novel single-balloon enteroscopy for diagnosis and treatment of the small intestine: preliminary experiences. Endoscopy 2008;40:11-5.

24. Akerman PA, Agrawal D, Cantero D, Pangtay J. Spiral enteroscopy with the new DSB overtube: a novel technique for deep peroral smallbowel intubation. Endoscopy 2008;40:974-8.

25. Domagk D, Mensink P, Aktas H, Lenz P, Meister T, Luegering A, et al. Single vs. double-balloon enteroscopy in small-bowel diagnostics: a randomized multicenter trial. Endoscopy 2011;43:472-6. 
26. May A, Manner H, Aschmoneit I, Ell C. Prospective, cross-over, single-center trial comparing oral double-balloon enteroscopy and oral spiral enteroscopy in patients with suspected small-bowel vascular malformations. Endoscopy 2011;43:477-83.

27. Cellier C. Obscure gastrointestinal bleeding: role of videocapsule and double-balloon enteroscopy. Best Pract Res Clin Gastroenterol 2008; 22:329-40.

28. Ohmiya N, Yano T, Yamamoto H, Arakawa D, Nakamura M, Honda W, et al. Diagnosis and treatment of obscure GI bleeding at double balloon endoscopy. Gastrointest Endosc 2007;66:S72-S77.

29. Gross SA, Stark ME. Initial experience with double-balloon enteroscopy at a U.S. center. Gastrointest Endosc 2008;67:890-7.

30. Pérez-Cuadrado E, Más P, Hallal H, Shanabo J, Muñoz E, Ortega I, et al. Double-balloon enteroscopy: a descriptive study of 50 explorations. Rev Esp Enferm Dig 2006;98:73-81.

31. Pennazio M. Diagnostic and therapeutic utility of double-balloon endoscopy in small-bowel bleeding. Tech Gastrointest Endosc 2008;10:77-82.

32. Douard R, Wind P, Panis Y, Marteau P, Bouhnik Y, Cellier C, et al. Intraoperative enteroscopy for diagnosis and management of unexplained gastrointestinal bleeding. Am J Surg 2000;180:181-4.

33. Lau WY, Fan ST, Wong SH, Wong KP, Poon GP, Chu KW, et al. Preoperative and intraoperative localisation of gastrointestinal bleeding of obscure origin. Gut 1987;28:869-77.

34. Lewis BS, Wenger JS, Waye JD. Small bowel enteroscopy and intraoperative enteroscopy for obscure gastrointestinal bleeding. Am J Gastroenterol 1991;86:171-4.

35. Ress AM, Benacci JC, Sarr MG. Efficacy of intraoperative enteroscopy in diagnosis and prevention of recurrent, occult gastrointestinal bleeding. Am J Surg 1992;163:94-8.

36. Desa LA, Ohri SK, Hutton KA, Lee H, Spencer J. Role of intraoperative enteroscopy in obscure gastrointestinal bleeding of small bowel origin. Br J Surg 1991;78:192-5.
37. Kendrick ML, Buttar NS, Anderson MA, Lutzke LS, Peia D, Wang KK, et al. Contribution of intraoperative enteroscopy in the management of obscure gastrointestinal bleeding. J Gastrointest Surg 2001;5: 162-7.

38. Kopácová M, Bures J, Vykouril L, Hladík P, Simkovic D, Jon B, et al. Intraoperative enteroscopy: ten years' experience at a single tertiary center. Surg Endosc 2007;21:1111-6.

39. Hartmann D, Schmidt H, Bolz G, Schilling D, Kinzel F, Eickhoff A, et al. A prospective two-center study comparing wireless capsule endoscopy with intraoperative enteroscopy in patients with obscure GI bleeding. Gastrointest Endosc 2005;61:826-32.

40. Jakobs R, Hartmann D, Benz C, Schilling D, Weickert U, Eickhoff A, et al. Diagnosis of obscure gastrointestinal bleeding by intra-operative enteroscopy in 81 consecutive patients. World J Gastroenterol 2006; $12: 313-6$

41. Hartmann D, Schmidt H, Schilling D, Kinze F, Eickhoff A, Weickert U, et al. Follow-up of patients with obscure gastrointestinal bleeding after capsule endoscopy and intraoperative enteroscopy. Hepatogastroenterology 2007;54:780-3

42. Kitiyakara T, Selby W. Non-small-bowel lesions detected by capsule endoscopy in patients with obscure GI bleeding. Gastrointestinal endoscopy $2005 ; 62: 234-8$.

43. Tee HP, Kaffes AJ. Non-small-bowel lesions encountered during double-balloon enteroscopy performed for obscure gastrointestinal bleeding. World J Gastroenterol 2010;16:1885-9.

44. Velayos B, Herreros de Tejada A, Fernández L, Aller R, Almaraz A, Del Olmo L, et al. Upper gastrointestinal findings detected by capsule endoscopy in obscure gastrointestinal bleeding. Rev Esp Enferm Dig 2009;101:11-9.

45. Richter JM, Christensen MR, Colditz GA, Nishioka NS. Angiodysplasia. Natural history and efficacy of therapeutic interventions. Dig Dis Sci 1989;34:1542-6. 